\title{
Influence of generation representation on reliability balance indicators and their support means in managing the development of electric power systems
}

\author{
Yurii Chukreev ${ }^{1, *}$ \\ ${ }^{1}$ Institute for Socio-Economic \& Energy Problems of the North Federal Research Center of the Komi Science Centreof the Ural \\ Branch of the Russian Academy of Sciences, Syktyvkar, Russia
}

\begin{abstract}
The issues of presentation generating equipment when solving the problem of substantiating the operational reserve of power in the UES of Russia are considered. The influence of the adopted composition of equipment, various modeling of capital and medium repairs, accounting for the energy supply of hydroelectric power plants on the values of indicators balance reliability and means their support is given.
\end{abstract}

\section{Statement the research problem}

The transformations that have taken place in the country over the past three decades have led to significant socio-economic changes, including in the power industry. Since the end of the century, there has been a significant reduction in electricity consumption and power. This naturally reflects on the issues of justifying the development electric power industry, which in the period 1980-2000 practically did not receive due attention. Only in 2010 the work on planning the development UES of Russia was resumed. It should be understood that the changes have taken place in the country and in the electric power industry in particular, one way or another, should affect the criteria for making certain managerial decisions.

In modern conditions, the capacity balances planned in the annual work performed by JSC SO UES and PJSC FGC UES "Scheme and program for the development of the country's UES for a seven-year period" (SPD) have significant excess generating capacity. This, together with the aging of equipment, is the main reason for a significant increase in the specific indicators of the power cost in comparison with foreign practice. The Russian indicators of the unit cost of $1 \mathrm{~kW}$ of installed capacity are almost 2 times higher than those in the USA, Europe and China.

The power balance is characterized by input and output parts. The incoming part is installed capacity minus various kinds of restrictions. In addition to the maximum load and power export values planned with varying degrees of error, the consumable part includes the parameter of the normative power reserve (NPR). In the tasks of planning the development of EPS, it is conditionally divided into three components: repair, operational and strategic. The repair reserve is intended to compensate for the decrease in the capacity used in the balance, associated with the withdrawal of generating equipment for scheduled repairs (current, average, capital). The operational reserve is designed to compensate for unscheduled (emergency) outputs for the repair of the main generating equipment and accidental load changes caused by temperature fluctuations.

In the context of transition the electric power industry to market relations and generating capacity freed up in the UES of Russia, the task of justifying the NPR value when planning the development UES of Russia should undergo significant changes. This also applies to the task of assessing the balance reliability indicators (BRI), which is an integral part in justifying the NPR. This applies to both the methodological part and the larger informational part. Unfortunately, the absence of scientifically substantiated provisions for making decisions to ensure balance reliability in relation to modern conditions leads to the use of the normative indicator the integral probability of a power shortage [1, 2] $\left(\mathrm{J}_{\mathrm{d}}=0.004\right)$, adopted in the pre-perestroika period. The article examines the influence of generating capacity modeling on the substantiation the means of ensuring balance reliability in relation to the changed conditions of the functioning and development electric power industry in comparison with the pre-perestroika period.

\section{Composition of generating equipment}

Generation is characterized by the installed capacity of the power plant generators. Their level is consistent with industry reporting provided by generating companies. When planning the development of EPS, both earlier and today, the task remains to determine the capacity of power plants and their structure, which is necessary to reliably cover the expected load demand. In the pre-perestroika period in the UES of the former USSR, there was a problem of capacity deficits, and determination the NPR was carried out by justifying the commissioning of capacities that were not enough to cover the existing deficit. In this case, in the model of generating capacity, when assessing the BRI, all

Corresponding author: chukreev@iespn.komisc.ru 
generators of power plants that can bear the load were taken into account $[3,4]$.

In modern conditions, the UES of Russia is characterized by the presence of significant surpluses of generating capacity. This state requires taking into account not all generators, but only those involved in covering the load, when assessing the BRI and justifying the operational component of the NPR. They are determined during the competitive capacity selection procedure (CSP). Thus, there is a certain inconsistency. On the one hand to justify the value of NPR and the demand for capacity it is necessary to know the composition of the generating equipment to cover the load (demand). On the other hand, this composition can be determined only as a result of the CSP, in which the value of demand for capacity serves as the basis.
The most difficult is to determine the average value of the accident rate generating equipment that does not take part in covering load. A great help for the adequate implementation of this issue can be use the retrospective information on the long-term power takeoffs of CSP carried out in accordance with the Decree of the Government of the Russian Federation of December 27, 2010, No. $1172^{1}$ (RF GD No. 1172). However, such information cannot be found in the public domain.

The emergency component values of the operational power reserve and their changes under different scenarios for accounting for unused generating equipment are given in Table 1. The results were obtained with the use software "Orion-M" [4]. The design scheme UES of Russia and the information content of the problem were obtained during joint

Table 1. Values of the operational power reserve and their changes under various scenarios for accounting unused generating equipment

\begin{tabular}{|c|c|c|c|c|c|c|c|c|c|c|}
\hline \multirow{2}{*}{ Territorial zone } & \multirow{2}{*}{$\begin{array}{c}\text { Installed } \\
\text { capacity, } \\
\text { MW }\end{array}$} & \multirow{2}{*}{$\begin{array}{l}\text { Maximum } \\
\text { load, } \\
\text { MW }\end{array}$} & \multicolumn{4}{|c|}{$\begin{array}{l}\text { Estimated operational power } \\
\text { reserve ("Orion-M"), MW / \% }\end{array}$} & \multicolumn{4}{|c|}{$\begin{array}{c}\text { Change in operating power reserve } \\
\left(\Delta R_{\mathrm{op}}\right), \mathrm{MW} / \%\end{array}$} \\
\hline & & & 1 & 2 & 3 & 4 & $\begin{array}{l}\text { according } \\
\text { formula (1) }\end{array}$ & 2 & 3 & 4 \\
\hline UES of Russia (without East) & 239948 & 155860 & $\begin{array}{l}9837 \\
6,31\end{array}$ & $\begin{array}{l}5387 \\
3,46\end{array}$ & $\begin{array}{c}8672 \\
5,56\end{array}$ & $\begin{array}{l}7002 \\
4,49\end{array}$ & $\begin{array}{c}2695 \\
1,73\end{array}$ & $\begin{array}{l}4450 \\
2,86\end{array}$ & $\begin{array}{l}1165 \\
0,75\end{array}$ & $\begin{array}{r}2835 \\
1,82\end{array}$ \\
\hline European with the Urals & 187919 & 125634 & $\begin{array}{l}7410 \\
5,90\end{array}$ & $\begin{array}{l}4070 \\
3,24 \\
\end{array}$ & $\begin{array}{c}6550 \\
5,21\end{array}$ & $\begin{array}{c}5275 \\
4,20\end{array}$ & $\begin{array}{c}2008 \\
1,60\end{array}$ & $\begin{array}{l}3340 \\
2,66\end{array}$ & $\begin{array}{r}860 \\
0,69\end{array}$ & $\begin{array}{r}2135 \\
1,70\end{array}$ \\
\hline Siberia & 52029 & 30126 & $\begin{array}{r}2427 \\
8,06 \\
\end{array}$ & $\begin{array}{l}1317 \\
4,37 \\
\end{array}$ & $\begin{array}{r}2122 \\
7,04 \\
\end{array}$ & $\begin{array}{l}1727 \\
5,73\end{array}$ & $\begin{array}{l}692 \\
2,30 \\
\end{array}$ & $\begin{array}{l}1110 \\
3,68 \\
\end{array}$ & $\begin{array}{l}305 \\
1,01 \\
\end{array}$ & $\begin{array}{r}700 \\
2,32 \\
\end{array}$ \\
\hline
\end{tabular}

Consider the influence of a different set generating equipment on the means of ensuring reliability. For the purity of experiment, the substantiation of operational component the NPR will be carried out without taking into account the load forecast error caused by the temperature factor. In other words, only the change in the emergency component of the operational power reserve is estimated when the generators are varied in the composition of the generating equipment used to cover the demand.

It is quite obvious that a change in the composition of generating equipment due to the withdrawal of inefficiently operating units should lead to a change in the operational power reserve $\left(R_{\text {op }}\right)$ calculated for a known and unchanged composition of equipment. The magnitude of this change $\left(\Delta R_{\mathrm{op}}\right)$ depends primarily on mathematical expectation of the average statistical value emergency component of the removed equipment. The approximate value of this change can be determined by the expression:

$$
\Delta R_{\mathrm{op}}=R_{\mathrm{op}}-\left(P_{\text {inst }}-P_{1}\right) \times q_{\mathrm{av}}
$$

It has a $P_{\text {inst. }}$ - installed capacity of power plants, determined by the composition of existing equipment; $P_{1}$-load coverage power required to achieve the required reliability level and equal to the sum of the maximum load $\left(P_{\max }\right)$ and the value of $R_{\mathrm{op}} ; q_{\mathrm{av}}-$ the average statistical value of accident rate the equipment removed and not participating in the load coverage (in the power balance - these are various kinds of restrictions, power surpluses, components of the planned and strategic power reserves). research $^{2}$ with SO UES JSC.

As a calculation scheme, we used a scheme in the form of combined EPS (Fig. 1), the information for 2022

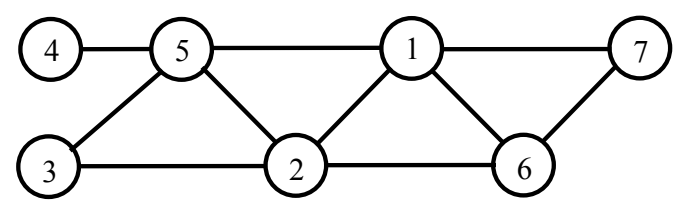

Fig. 1 - Model of the calculation scheme UES of Russia.

1 - Urals; 2 - Middle Volga; 3 - South;

4 - North-West; 5 - Center; 6 - Kazakhstan; 7 - Siberia.

is tied to the work of SPD 2016-2022. In Table 1, the information is given only for the two price zones allocated in modern conditions used in CSP. The numbers mean the following scenarios for accounting for unused generating equipment:

1 Resolution of the Government Russian Federation of December 27, 2010, No. 1172 (as amended on January 19, 2018) "On approval of the Rules for the wholesale electricity and capacity market and on amendments to some acts of the Government Russian Federation on the organization functioning of the wholesale electricity market and power ".

${ }^{2}$ R\&D report Substantiation of the normative values components full reserve of capacity in the context of the UES of Russia as a whole when planning their development. / Syktyvkar, 2016-66 p. (Agreement Institute for Socio-Economic \& Energy Problems of the North Federal Research Center of the Komi Science Centre of the Ural Branch of the Russian Academy of Sciences with JSC SO UES, No. 926 dated September 22, 2016) 
1 -based on the invariability of existing surplus equipment;

2 and 3 -taking into account the accident rate of the removed equipment, assuming the conclusions largest in terms of power generators (2) and the smallest (3);

4 -taking into account the accident rate of the removed generating equipment, assuming that their relative average values are approximately equal to the existing values.

The results are presented in table 1 disappointing. The presence of sufficiently large power surpluses at the present time significantly distorts the results of substantiating the standard power reserve. Even in the most unrealistic scenario for the withdrawal of the smallest in terms of power generators with insignificant accidents, the overestimation of the operating power reserve exceeds $0.75 \%$ maximum load of the power system (more than $1 \mathrm{GW}$ ), in the most realistic (probable) scenario - more than $1.8 \%$ (more $2 \mathrm{GW}$ ). This indicates need to revise the normative adopted at the end of the last century to justify the power reserve.

\section{Overhaul and medium repairs of generating equipment}

Until the end of the 80 s of the last century, due to the lack of generating capacity in the UES of the former USSR, overhaul and medium repairs of equipment were carried out during periods of seasonal load drops. This made it possible to use, with a sufficiently high degree of reliability, for calculating the BRI and justifying the means of its provision, the average December daily load schedule, lasting the whole year $[3,5]$, and thereby, significantly simplify the models of generating capacity and load when assessing the BRI. In fig. 2 shows an annual graph of seasonal (monthly) load decreases. The area where capital and medium repairs $\left(R_{\mathrm{cr}}\right)$ fit into the failure of the annual load schedule reduction is shaded in gray. The bold dashed line shows the conditional maximum load lasting the whole year.

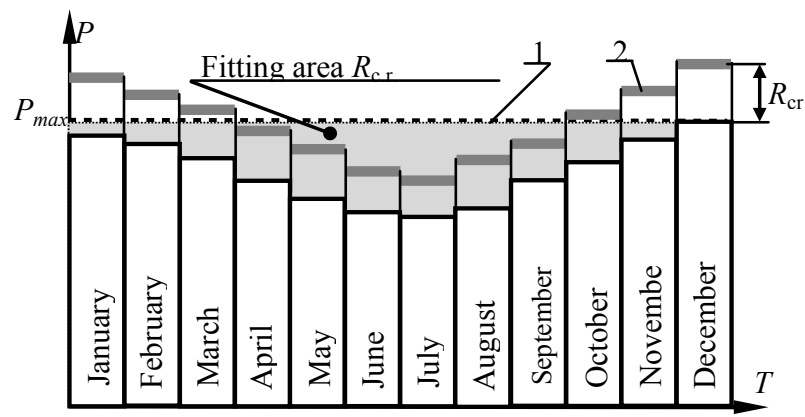

Fig. 2 - Understanding the issue of the impact of accounting for capital and medium repairs when justifying the regulatory

The substantiated value of the normative BRI in the pre-perestroika period was associated with the specific indicators of the cost of the generating capacity being commissioned, losses from unreliability and the assumption described above about the representation of the load by the daily December schedule lasting the whole year. At present, these concepts have gone into oblivion, but the normative indicator balance reliability value in the form of the integral probability of absence $\left(J_{\mathrm{d}}=0.004\right)$ or appearance $(\rho=0.996)$ of a power deficit remains and is still used [1].

With the launch of the capacity market in 2006, the norms for the duration and frequency of major and medium repairs, as well as promising five-year plans for repairs of the main equipment of power plants, have lost their regulatory role. A significant reduction in power consumption has led to the emergence of sufficient surplus capacity and an improving the regime and balance situation in the UES of Russia. The introduction rules for the wholesale electricity (capacity) market and the financial capabilities of generating companies made it possible to carry out repairs in the autumn-winter period. This led to a change in the statistical reporting of major and medium repairs.

This state with major and medium repairs completely changes the concept of the model representation load. It should be represented not by one average daily chart of December, but at least by daily charts of its seasonal (monthly) declines. In fig. 2 shows the increment in the load on the component of capital and medium repairs $\left(R_{\mathrm{cr}}\right)$ by months of the year. The seasonal schedule of load changes taking into account the new paradigm of capital and medium repairs in Fig. 2 is highlighted in gray

The question of assessing the impact of the presentation in model of assessing the BRI and substantiating the means of its provision for capital and medium repairs becomes interesting (Table 2). The results are presented for the model of the calculation scheme UES of Russia described in Section 1 (Fig. 1) with different accounting in the model for estimating the BRI of major and medium repairs.

Results shows that modeling capital and medium repairs by changing the load (or generation) by months of the year (graph 2 in Fig. 2) leads to a rather significant reduction in the operational component of the regulatory capacity reserve (about 4\% for the UES of Russia as a whole ) subject to the normative BRI $\rho=0.996$. This is the expected result. At the same time, with such an approach to justifying the NPR for the December maximum load, its other component will increase planned capital and medium repairs of equipment. According to the specialists of SO UES JSC, this component increases in the European part UES of Russia by at least $4 \%$, in Siberia it is somewhat higher. At the same time, one must be aware that the value of the decrease in the operational component NPR was obtained with the decision-making criterion developed for completely different conditions representing the power consumption mode. This requires the conduct of research, including relying on foreign experience in solving similar problems.

The power consumption regime adopted in the study by months of the year is conditional due to lack of information. It was obtained from the reporting materials of SO UES JSC. It is not entirely correct in context of months in BRI assessment model to describe random load changes (they were obtained in relation to the cold period of December), communication capacity, and much more. The results shows that the market conditions caused by the possibility of carrying out planned capital and medium repairs of 

repairs equipmen

\begin{tabular}{|c|c|c|c|c|c|c|c|}
\hline \multirow[b]{2}{*}{ Indicators } & \multirow{2}{*}{$\begin{array}{l}\text { UES of Russia } \\
\text { without East }\end{array}$} & \multicolumn{6}{|c|}{ Name } \\
\hline & & Ural & $\begin{array}{l}\text { Middle } \\
\text { Volga }\end{array}$ & South & Northwest & Centre & Siberia \\
\hline Maximum load & 155860 & 37390 & 17096 & 16831 & 15151 & 39266 & 30126 \\
\hline \multicolumn{8}{|c|}{ Operational power reserve } \\
\hline $\begin{array}{l}\text { 1. When using power consumption } \\
\text { mode } 1 \text { (Fig. } 2 \text { ), MW / \% }\end{array}$ & $\begin{array}{c}15610 \\
10,02\end{array}$ & $\begin{array}{l}4894 \\
13,09\end{array}$ & $\begin{array}{c}1078 \\
6,31\end{array}$ & $\begin{array}{l}1619 \\
9,62\end{array}$ & $\begin{array}{l}1629 \\
10.75\end{array}$ & $\begin{array}{l}3365 \\
8.57\end{array}$ & $\begin{array}{l}3025 \\
10.04\end{array}$ \\
\hline $\begin{array}{l}\text { 2. When using power consumption } \\
\text { mode } 2 \text { (Fig. 2), MW / \% }\end{array}$ & $\begin{array}{l}9485 \\
6,09\end{array}$ & $\begin{array}{l}3444 \\
9,21\end{array}$ & $\begin{array}{l}378 \\
2,21\end{array}$ & $\begin{array}{l}894 \\
5,31\end{array}$ & $\begin{array}{c}1004 \\
6,63\end{array}$ & $\begin{array}{l}1975 \\
5,03\end{array}$ & $\begin{array}{l}1790 \\
5,94\end{array}$ \\
\hline \multicolumn{8}{|c|}{ BRI for the best option } \\
\hline$L O L H, \mathrm{~h} /$ year & 8,796 & 3,124 & 3,118 & 3,131 & 3,121 & 3,116 & 3,118 \\
\hline
\end{tabular}

equipment in December, while leaving the reliability normative $\rho=0.996$, does not lead to a significant increase in the value of normative power reserve. A decrease in its operational component is compensated by an increase in the repair component required for scheduled repairs.

Of particular interest is the question of comparing the normative values BRI adopted to substantiate the values of operational power reserve in our country with the foreign Western European analogue - Loss of Load Hours (LOLH) [6]. It should be noted that foreign standards for BRI haven't economic justification. They are accepted at the expert level.

The last line table 2 shows BRI in LOLH form, obtained for the optimal variant fitting major repairs into the seasonal schedule of load reduction (in Fig. 2, dashed line 1), but calculated using the seasonal reduction schedule (in Fig. 2, gray lines 2). In the aspect of making managerial decisions, the BRI used in our country $\mathrm{J}_{\mathrm{d}}=$ 0.004 is in good agreement with the $L O L H$ indicator used in foreign practice. In accordance with the table 2 this indicator for the optimal variant distribution operating reserve obtained using graph 1 in Fig. 2 for all UESs is approximately $3,2 \mathrm{~h} /$ year. For information, in France $\mathrm{LOLH}=3$ hours/year, in $\mathrm{UK}=4$ hours/year, in Ireland $=8$ hours $/$ year.

\section{Power supply of hydroelectric power plants of the UPS of Siberia}

As already noted, the task of assessing the PBN is an integral part of solving the problem of substantiating the operational component of the regulatory power reserve. It is based on the solution of two interrelated stages $[3,4]$ :

- the formation of random load values caused by the influence temperature factor and the states of decreasing the generating capacity, caused by unscheduled withdrawals for emergency repair of the power plants equipment;

- assessment of the formed states of provision of the load in the territorial zones.

So far, in the BRI EPS assessment models the types of the generating equipment involved in meeting the consumer demand have not been specified. Moreover, this was justified because in estimating the BRI out of the multitude of randomly formed states of generating capacity and load is less than a percent. It should be noted that only in these deficit states the generating capacity is fully used. In the states without a deficit, which are more than $99 \%$, the generating power exceeds the load. These states do not affect the BRI, so from the point of view of providing a power balance, the generation can be redistributed as much as possible between different types of stations (HPP, TPP, NPP, RES).

The contribution of a hydroelectric power station in covering the load in the absence of a deficit state can be taken into account only when the power reduction functions caused by the output of the equipment in the unscheduled (emergency) repair can be formed separately for thermal, including nuclear power plants and for hydro units of seasonal (annual) flow control. The methodology for such modeling and assessment of the formed states is presented in [7]. This approach to modeling opens up the possibility of determining the necessary addition to the value of the NPR caused by insufficient energy supply of HPPs in dry years. This requires two calculations to determine the operational power reserve - with the predicted value of electricity production at hydroelectric power plants and for a dry year.

In both calculations, the operational reserve of capacity remains unchanged, but due to the change in the power supply of the hydroelectric power station, the power generating capacity of the participating payers will be redistributed between the HPP and TPP with NPP. The difference in redeployment will be a premium to the operational and therefore normative capacity reserve due to the reduction in the energy supply of the hydroelectric power station in the low-water years. The most difficult in this approach is the uncertainty of information on the energy supply at a HPP.

The application of the developed methodology showed the presence of a strict relationship between the percentage of addition to the operational power reserve ( $\Delta W_{\text {d.y.,\% }}$ ), the percentage of reduction in electricity production at HPPs of Siberia in dry years ( $\left.\delta W_{\text {d.y.,\% }}\right)$, and the ratio predicted value of electricity production at HPPs of Siberia $\left(W_{\text {gh.HPP }}\right)$ to the total volume of electricity production at all stations types in Siberia $\left(W_{\Sigma}\right)$ :

$$
\Delta W_{\text {d.y. }, \%}=\delta W_{\text {d.y., } \%} \times W_{\text {gh.HPP }} / W_{\Sigma}
$$

In the regulatory and technical documentation RF GD No. 1172 (clause 107), an addition to the NPR of Siberia was adopted in the amount $8.55 \%$ of the combined maximum load. In accordance with expression (2), such a value of the additive can be achieved in the case when difference in electricity production at the HPP Siberia for the calculated and dry year will amount to $16.7 \%$. A natural question arises - what amount of electricity production at the hydroelectric power plants of Siberia, when justifying the NPR, should be taken as a 
calculated one? This is a rather important and unexplored issue in the problem of justifying the NPR. Its study was not in demand in the context of industry centralized management. At that time, the task was not to identify the most effective capacities due to their banal insufficiency (the frequency in the system was almost always below the standard value). In modern conditions of excess capacity, the issue of accounting for the energy supply of hydroelectric power plants becomes quite urgent.

Two options are possible to accept the calculated value of electricity production at the Siberia hydroelectric power plants. The first one is acceptance of the projected with a high-probability to be implemented (formulation from the Electricity Balance in the work of SPD) electricity production volumes. The second option is the acceptance of an average value based on the analysis of retrospective information on the actual electricity production.

Analysis retrospective information presented in [7] shows that the difference in electricity production at HPPs Siberia of $16.7 \%$ can be provided only when considering the maximum deviations the predicted parameters of electricity production for a probable scenario and for a dry year. The key phrase here is "predicted parameters". The more we predict the gap between the parameters, the greater the addition to the NPR value. It is most correct in this matter to consider the ratio actual production of electricity at hydroelectric power plants with its predicted value, obtained on the basis of processing retrospective information. Such processing is given in [7]. The decrease in electricity production at HPPs Siberia in dry years should not exceed $7.0 \%$ on average, and taking into account actual deviations, no more than $9.2 \%$. This corresponds addition to the normative power reserve not $8.55 \%$, adopted in the RF GD No. 1172, but, in accordance with expression (2), from 3.58 to $4.72 \%$.

\section{Conclusions}

1. The presence of significant power surpluses caused by a decrease in electricity consumption requires a revision composition of the generating equipment involved in covering the load. Failure to take this factor into account leads to an overestimation of the operational component regulatory capacity reserve for the UES of Russia as a whole from 0.7 to $2.8 \%$ of the combined maximum load. In the most realistic (probable) scenario of equipment withdrawal, the overestimation is more than $1.8 \%$ (more than $2 \mathrm{GW}$ ).

2. The rules of the wholesale market and the financial capabilities of generating companies, together with the improvement of the regime and balance situation in the UES of Russia (a significant reduction in electricity consumption), made it possible to carry out major and medium repairs of generating equipment in the autumnwinter period. This completely violated the simplifications introduced in the pre-perestroika period on the representation of the power consumption regime in the models for assessing the indicators of balance reliability and the means of ensuring it. In modern conditions, it is necessary to revise the methodological principles for assessing balance reliability indicators and develop new approaches to their standardization when substantiating the means of ensuring reliability.

3. The dependence of electricity production at hydroelectric power plants on water availability requires improving the model for justifying the operational component of the regulatory power reserve. The main difficulty is information support for the production of electricity at hydroelectric power plants in dry years. Analysis of retrospective information showed that the difference between the planned value of electricity production, taking into account the actual and for a dry year at hydroelectric power plants should not exceed $9.2 \%$. This corresponds to an addition to the normative capacity reserve not $8.55 \%$, adopted in the Decree of the Government of the Russian Federation No. 1172, but only $4.72 \%$.

\section{References}

1. Metodicheskie rekommendatsii po proektirovaniyu razvitiya energosystem. (Utverzhdeno Prikazom Minenergo Rossii ot 30 June 2003, № 281). M.: Minenergo RF, CO 153-34.20.118-2003.

2. Volkenau I.M., Zeiliger A.N., Khabachev L.D. Ekonomika formirovaniya elektroenergeticheskikh sistem. M.: Energoatomizdat, 1981, 320 p.

3. Chukreev Yu.Ya. Modeli obespecheniya nadyozhnosti elektroenergeticheskikh system. Syktyvkar: Komi SC UrO RAN, 1995,176 p.

4. Chukreev Yu.Ya., Chukreev M.Yu. Modeli otsenki pokazateleyi balansovoyi nadezhnosty pri upravlenii razvitiem elektroenergeticheskikh system. Syktyvkar: Komi SC UrO RAN, 2014, 207 p.

5. Markovich I.M. Rezhimy energeticheskikh sistem. M.: Energiya, 1969, 351 p.

6. Billinton, R. Reliability Evaluation of Power Systems. Second Edition / R. Billinton, R.N. Allan. New York and London: Plenum Press, 1996, 509 p.

7. Chukreev Yu.Ya., Chukreev M.Yu. Methodological principles of accounting for hydroelectric power plants in the task of ensuring the balance reliability UES of Russia // Methodological Problems in Reliability Study of Large Energy Systems: Volume 70. Methodical and practical problems of power systems reliability / otv. ed. N.I. Voropai / Book 1. Irkutsk (2019), 54-63 p. 